\title{
Trajetórias Profissionais de DOUTORES EM Educação em CiênCias e Matemática egressos do Programa da Amazônia Legal
}

\author{
PROFESSIONAL TRAJECTORIES OF PHD IN EDUCATION IN SCIENCE AND \\ MATHEMATICS GRADES OF THE PROGRAM OF THE LEGAL AMAZON
}

DOI: $\underline{\text { 10.23926/RPD.2526-2149.2020.v5.n3.p1884-1908.id925 }}$

\author{
Ana Claudia Tasinaffo \\ Alves \\ Doutora em Educação em \\ Ciências e Matemática \\ (UFMT/REAMEC) \\ Professora do Instituto \\ Federal de Mato Grosso \\ (IFMT) \\ anatasinaffo@gmail.com
}

\section{Irene Cristina de \\ Mello}

Doutora em Educação

(USP/São Paulo)

Professora do Departamento de Química da Universidade Federal de Mato Grosso

(UFMT)

ireneufmt@gmail.com
Resumo: Neste artigo, apresentamos uma pesquisa realizada com egressos do Programa de Pós-Graduação da Rede Amazônica de Educação em Ciências e Matemática (REAMEC). O objetivo era analisar as percepções de doutores titulados na primeira turma sobre as contribuições desta formação para sua trajetória profissional. Foi realizado um levantamento do perfil de 29 egressos por meio de consultas aos currículos Lattes dos egressos e entrevista com onze deles. $\mathrm{O}$ estudo mostrou que a formação doutoral contribuiu para a inserção em programas de mestrado na área de Educação em Ciências e Matemática, para um significativo aumento da produção científica, e que novos mestrados foram constituídos com a formação dos doutores da primeira turma. E, apesar da formação em rede, em sua maioria, os egressos continuam isolados e não mantém os trabalhos e pesquisas em rede, demonstrando que a formação por si só não é fator determinante para tal configuração.

Palavras-chave: Doutorado em Rede. REAMEC. Educação em Ciências e Matemática. Trajetória Profissional. Amazônia Legal.

\begin{abstract}
In this article, we present a research carried out with graduates of the Graduate Program of the Amazon Network of Education in Science and Mathematics (REAMEC). The objective was to analyze the perceptions of $\mathrm{PhD}$ graduated in the first group about the contributions of this training to their professional trajectory. A survey of the profile of 29 graduates using the Lattes curriculum of the graduates of the first class and interviews with eleven of them. The study showed that the doctoral training contributed to the inclusion in master's programs in the area of Science and Mathematics Education, for a significant increase in scientific production, and that new masters were constituted with the training of first class $\mathrm{PhD}$. And, in spite of the network formation, the majority of the graduates remain isolated and do not keep the works and researches in network, demonstrating that the formation by itself is not determinant factor for such configuration.
\end{abstract}

Keywords: PhD in Network. REAMEC. Teaching Science and Mathematics. Professional Trajectory. Legal Amazon. 


\section{INTRODUÇÃO}

No Brasil, temos acompanhado nos últimos anos transformações em vários cenários, políticos, econômicos, sociais. Na área educacional, especificamente no ensino superior foram muitas as mudanças, que vão desde a interiorização do ensino, fomentadas sobretudo pelo programa de Reestruturação e Expansão das Universidades Federais (REUNI), até a considerável ampliação da oferta de programas e cursos de pós-graduação stricto senso.

Em termos numéricos, assistimos a uma significativa expansão na pós-graduação brasileira, o que pretensamente tem se refletido em mais qualidade no ensino, pesquisa e extensão em vários níveis e segmentos. Além de contribuir com a produção de conhecimentos para diversas áreas, essas pós-graduações têm qualificado profissionais, destacando-se um crescimento expressivo na área educacional com a formação de muitos mestres e doutores.

Para Silva Junior et al. (2013) houve uma expansão no número de matrículas entre os anos de 1995 a 2010, sendo que o aumento no número de matrículas da pós-graduação foi de 155,1\% e da graduação de 77,4\%, em 2017 foram 361.530 matrículas entre mestrados e doutorados (BRASIL, 2018). Se por um lado o número de programas de pós-graduação cresceu em todo o país, a proporção não é a mesma em todas as regiões brasileiras. Ao observamos a região da Amazônia Legal (AL) notamos que a oferta de programas, em especial das áreas de avaliação Educação e Ensino, apresentam quantitativo inferior ao de regiões como Sul e Sudeste.

De acordo com informações disponíveis na plataforma Sucupira da Capes , encontramos um total de 4.381 programas de pós-graduação stricto sensu recomendados com um total de 6.472 cursos (mestrados acadêmicos, mestrados profissionais e doutorados) desses, cento e um são cadastrados na área Básica Ensino de Ciências e Matemática (dentro da área de avaliação Ensino/ Capes), sendo que a maior concentração desses programas está na região Sul e Sudeste. A desproporcionalidade na oferta de programas de pós-graduações nas regiões brasileiras gera vários problemas, como por exemplo, poucos cursos de mestrados e doutorados, baixo índice de pesquisas e a necessidade de deslocamento dos docentes das instituições de ensino superior (IES) às universidades de outros estados do Brasil, sobretudo Sul e Sudeste. Ademais, muitos doutores oriundos de outros Estados e concursados em instituições do ensino superior que compõem a AL, desistem da vaga ou solicitam redistribuição para outras regiões.

As mudanças no cenário educacional proporcionaram também um aumento na oferta de cursos superiores, consequentemente o número de professores atuando no ensino superior cresceu, mas muitos desses profissionais iniciam sua atuação sem formação em nível de 
mestrado ou doutorado. Um dos desafios que o professor do ensino superior encontra é o entendimento da indissociabilidade ensino, pesquisa e extensão. Para tanto, a formação profissional é imprescindível, e a profissão docente se constrói desde a formação inicial e continua à medida que se insere na carreira e busca uma formação continuada.

O professor sem a formação necessária para a atuação nesse nível de ensino poderá ter muitas dificuldades em colocar em prática a tríade ensino, pesquisa e extensão. Teoricamente, a pós-graduação poderá contribuir sobremaneira na superação de tal desafio, mas como cursar mestrado e/ou doutorado trabalhando em uma região onde existem poucas oportunidades? Assim sendo, a desproporcionalidade de acesso e oportunidade em programas de doutorado, especialmente na área de Ensino de Ciências e Matemática, tornou-se um problema para quem trabalha e reside em regiões como a Amazônia Legal.

A formação profissional na área de Educação na região da $\mathrm{AL}$ e os números de instituições que ofertam licenciatura vem crescendo, sobretudo no interior dos estados. Indicadores diversos nos mostram a necessidade de formar professores de Química, Física, Matemática e Biologia para a educação básica. Para tanto, precisamos de doutores, sobretudo na área de Ensino de Ciências e Matemática, para atuarem nesses cursos de formação de professores.

Diante desta situação, pesquisadores das instituições federais e estaduais da região da Amazônia Legal se associaram formando uma rede que busca alavancar pesquisas e formação de pesquisadores na área de Educação em Ciências e Matemática. Surgia, em 2006, a Rede Amazônica de Educação em Ciências e Matemática (REAMEC). O projeto da REAMEC surge como uma das metas do Programa Acelera Amazônia, criado pela Capes, que previa um fundo para apoio à mobilidade de pessoal e o seu objetivo principal era ampliar o número de mestres e doutores para a região, devido a carência de docentes das licenciaturas com doutorado na área básica de Ensino de Ciências e Matemática.

Além da carência de docentes doutores, tem-se no país uma pequena disponibilidade de doutores que fazem pesquisa na área de Ensino de Ciências e Matemática, o que em conjunto com a limitada oferta de vagas em programas de pós-graduação na área, que não suprem as necessidades existentes.

Com base nesses anseios, a REAMEC foi deflagrada durante o Fórum de Pró-Reitores de Pós-Graduação dos nove Estados que compõem a Região da AL no ano de 2006. Para a criação da proposta do programa em rede, foram realizados alguns encontros como seminários no Amapá e São Luís, em 2006 e 2007, respectivamente. 
Em agosto de 2007, em um workshop em Manaus, avançou-se na definição da estrutura inicial do projeto de doutorado acadêmico e da funcionalidade da rede. Nessa mesma reunião foram escolhidos professores doutores das IES da Região, como representantes estaduais, que constituíram a Comissão REAMEC, responsável pela elaboração da proposta ora apresentada.

Fazendo parte deste Programa, nosso tema de interesse é a trajetória profissional dos egressos da primeira turma do Programa de Pós-Graduação em Educação em Ciências e Matemática (PPGECEM) da REAMEC no contexto da Amazônia Legal.

Em 2018, a Rede possuía vinte e oito instituições associadas, sendo dez universidades federais, sete universidades estaduais, nove institutos federais e duas instituições privadas. A primeira turma ingressou em 2011 com trinta doutorandos e vinte nove conseguiram a titulação. A Rede já ofertou 224 vagas em cinco editais bienais.

Por ser um programa significativamente novo, não há ainda referências de estudos anteriores das contribuições que este tem promovido na região da Amazônia, carente de doutores na área de Ensino de Ciências e Matemática, nem quais impactos provocaram em relação à formação profissional de professores, criação de novos programas de pós-graduação, desenvolvimento de pesquisas e produção de conhecimento.

O objetivo da pesquisa foi analisar as percepções dos egressos doutores titulados na primeira turma, sobre as contribuições desta formação para sua trajetória profissional, bem como dos impactos para a área de Ensino de Ciências e Matemática na região da Amazônia Legal.

A questão problematizadora deste trabalho foi investigar "como o programa de PósGraduação em Educação em Ciências e Matemática da REAMEC promoveu mudanças na trajetória profissional na docência universitária do doutor egresso e colabora para que o egresso permaneça trabalhando em rede e mantendo grupos de pesquisa interinstitucionais para a região da Amazônia Legal?"

Para apresentação deste texto trazemos como discussão a seguir os desafios da atuação profissional de Mestres e Doutores na Educação Superior Brasileira.

\section{DESAFios da ATUAÇÃo PROFISSIONAL DE MESTRES E DOUTORES NA EDUCAÇÃo SUPERIOR BRASILEIRA}

O número de mestres titulados no Brasil tem crescido nos últimos anos como mostra a Figura 1, que é um gráfico encontrado nos estudos de Viotti et al. (2015, p. 60). Observando que nesta Figura estão computados os mestres titulados em mestrados acadêmicos e profissionais. 
Figura 1 - Mestres Titulados no Brasil 1996-2014

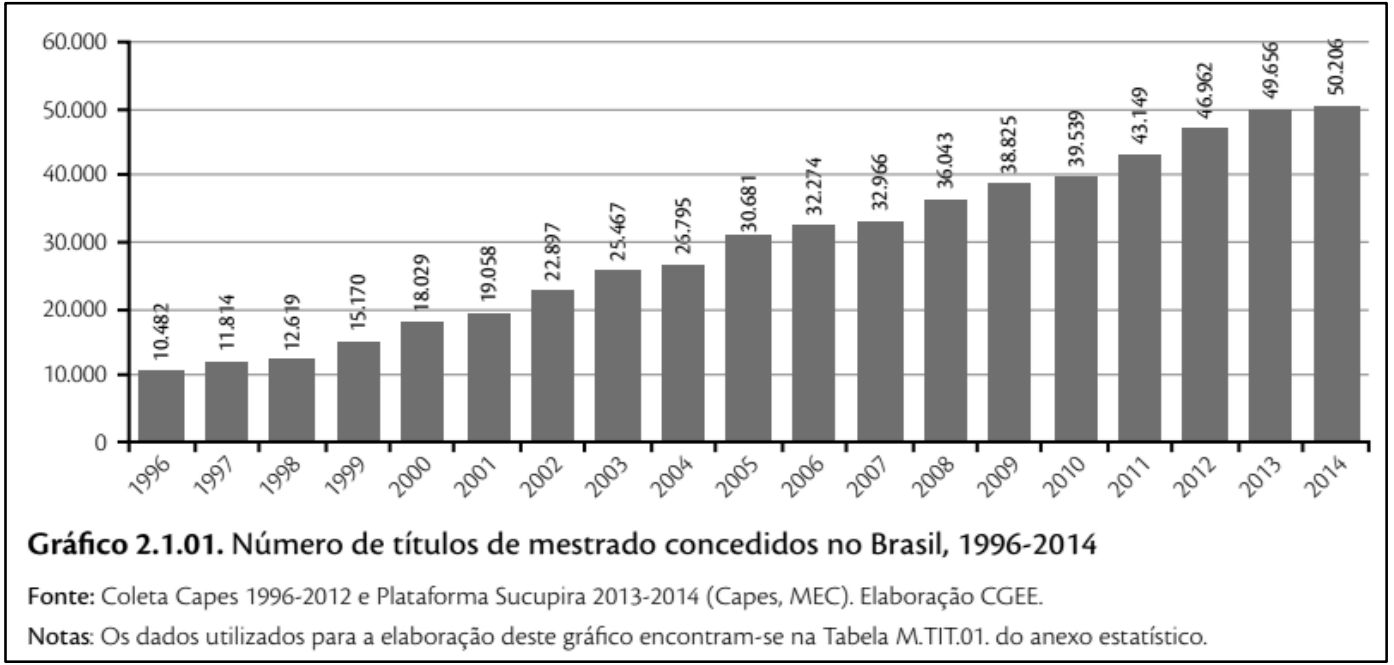

Fonte: Viotti et al. (2015, p. 60).

A Figura 2 mostra também uma evolução quantitativa no número de titulados em mestrados acadêmicos e profissionais separadamente.

Figura 2 - Mestres titulados no Brasil 1996-2014 (acadêmico e profissional)

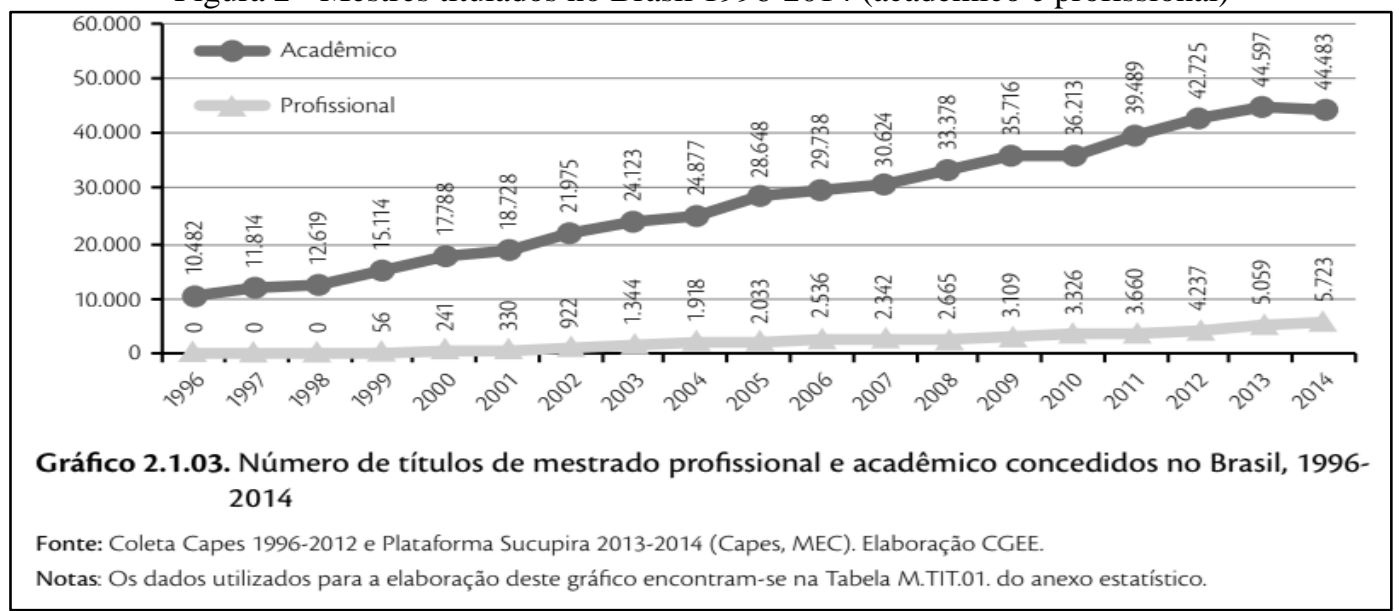

Fonte: Viotti et al. (2015, p. 60).

O número de doutores titulados teve um aumento de 486,2\% entre os anos de 1996 a 2014 (VIOTTI et al., 2015). E a Figura 3 mostra a evolução quantitativa dos titulados no Brasil no mesmo período referido anteriormente.

Figura 3 - Doutores titulados no Brasil 1996-2014 


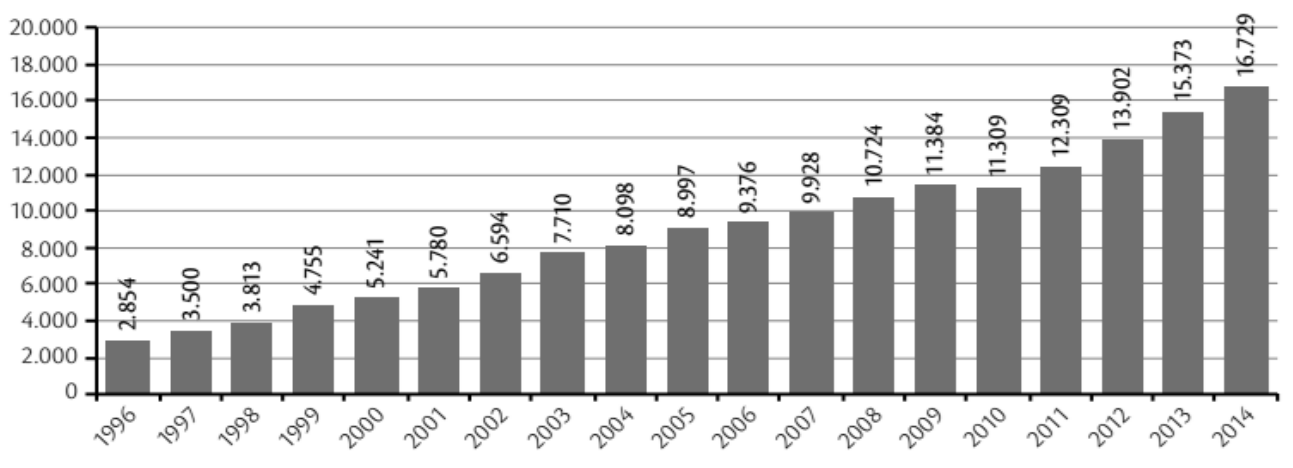

Gráfico 2.2.01. Número de títulos de doutorado concedidos no Brasil, 1996-2014

Fonte: Coleta Capes 1996-2012 e Plataforma Sucupira 2013-2014 (Capes, MEC). Elaboração CGEE.

Notas: Os dados utilizados para a elaboração deste gráfico encontram-se na Tabela D.TIT.01. do anexo estatístico.

Fonte: Viotti et al. (2015, p. 60).

Após essa breve apresentação do aumento significativo do número de mestres e doutores titulados no país nos últimos anos, nas mais variadas áreas, chamou-nos a atenção no estudo de Viotti et al. (2015) o percentual de doutores titulados por região no país. Do total dos doutores formados em 2014, a região Sudeste formou 60\%, seguida pela região Sul que formou 19\%, a região Nordeste titulou 14\%, enquanto as regiões Centro-Oeste e Norte titularam $5 \%$ e $2 \%$, respectivamente. As assimetrias na distribuição de programas de pós-graduação e titulados entre as regiões brasileiras ainda são de grandes dimensões atualmente.

Um estudo publicado por Velloso (2004, p. 591) mostra que os mestres e doutores no Brasil têm "atuação numa ampla diversidade de segmentos ocupacionais é, sem dúvida, a expressão que melhor resume o destino profissional de mestres titulados no país". Segundo o autor, os mestres e doutores das áreas básicas atuam principalmente nas universidades. E é sobre os desafios da atuação desses mestres e doutores na educação superior que pretendemos discutir a partir daqui.

Os professores mestres e doutores são os principais responsáveis pela educação em nível superior no Brasil. São estes profissionais que atuam nas IES, sobretudo nas públicas, conforme também apresentado por Velloso (2004). Para Cunha (2009, p. 82) "os saberes para a docência exigem uma preparação acadêmica numa perspectiva teórica e prática" além de "investimento constante que acompanhe os avanços investigativos e as mudanças paradigmáticas que envolvem os conhecimentos e redefinição do mundo do trabalho".

Nessa perspectiva, o docente precisa dos conhecimentos específicos de sua formação inicial, em nível de graduação, e ainda necessita de conhecimentos teóricos e práticos que podem ser adquiridos na formação em nível de pós-graduação. Cunha (2006, p. 258) salienta 
que o "domínio do conteúdo, por sua vez, deve ser alicerçado nas atividades de pesquisa que garantam a capacidade potencial de produção de conhecimento".

$\mathrm{Na}$ universidade, o trabalho docente se estabelece com a tríade indissociável ensinopesquisa-extensão. Cunha (2016, p. 5), ao tratar dos desafios da referida tríade, argumenta que

\begin{abstract}
Os docentes são pesquisadores qualificados e capazes de gerar conhecimentos na sua especialidade. Entretanto enfrentam muitas atividades acadêmicas para as quais não foram sistematicamente preparados. Entre estas atividades está à docência, nela entendida a capacidade de proporcionar ao aluno condições de autonomia e capacidade de gerar seu próprio conhecimento.
\end{abstract}

Para a referida autora, os desafios da docência são diversos, e corrobora com Pimenta e Anastasiou (2014, p. 165), que nos dizem que o professor que atua na universidade "precisa atuar como profissional reflexivo, crítico e competente no âmbito de sua disciplina, além de capacitado a exercer a docência e realizar as atividades de investigação”. É cobrado do docente o domínio de conhecimento de sua disciplina e a pesquisa, nesse sentido, pode contribuir para o aprofundamento dos conhecimentos de sua área.

A docência, para muitos professores mestres e doutores, é desafiadora, pois nem todos foram preparados para exercer a atividade docente. Muitos mestres e doutores se especializam, na sua área de formação, em conteúdos muito específicos das disciplinas que atuam. Assumem o desafio de ensinar, mas não foram preparados para isto. Muitos são excelentes pesquisadores, mas chegam às IES sem terem experiência docente.

Para Cunha (2016, p. 5), a atividade docente tem múltiplas dimensões. De acordo com a autora, a sala de aula e o contato com estudantes é a mais conhecida. E reforça ainda que

\footnotetext{
A complexidade da docência tem sido assumida no contexto contemporâneo, entendendo que há múltiplos saberes que precisam ser acionados nessa importante ação. São visíveis as transformações estruturais e tecnológicas que atingem a educação superior. Exigem elas saberes e sensibilidades diferenciadas para transitar na complexidade dos processos educativos que respondam as demandas da sociedade e dos educandos.
}

A sala de aula e a prática docente exigem diversos saberes, não basta saber o conteúdo, o que é importante, mas é necessário mobilizar conhecimentos de como ensinar os conteúdos, de como promover uma ação que propicie aos estudantes a aprendizagem, a autonomia na construção do próprio conhecimento e inseri-los nas atividades de pesquisa. A pesquisa em sala de aula é essencial para o desenvolvimento dos professores e estudantes.

Nesse sentido, muitos professores buscam conhecimentos que os auxiliem na prática docente, Cunha (2009) publicou um estudo em que mostra que, cada vez mais, professores de diversas áreas específicas buscam mestrados e doutorados em educação. De certo modo, 
entendemos que a atuação docente propicia a reflexão das práticas educativas e pode influenciar na busca de conhecimentos em ensino e educação.

Ainda falando dos saberes docentes, Tardif (2014, p. 36) escreve sobre a diversidade destes saberes, que vão além da mera transmissão de conhecimentos. $O$ autor define o saber docente como plural, resultante da combinação de quatro saberes, que são os "saberes oriundos da formação profissional e de saberes disciplinares, curriculares e experienciais". Ele define os saberes da formação profissional como os saberes que são adquiridos na instituição onde se estuda para a prática docente e que, nessa etapa, "não se limitam a produzir conhecimentos, mas procuram também incorporá-los à prática do professor" (TARDIF, 2014, p. 37).

Sobre os saberes disciplinares, o autor descreve que são aqueles adquiridos na graduação nas IES, como por exemplo os conteúdos específicos da Química, Física ou Matemática, de acordo com o curso estudado. Os saberes curriculares são aqueles que os professores se apropriam ao longo da sua carreira docente. Para ele, "estes saberes correspondem aos discursos, objetivos, conteúdos e métodos a partir dos quais a instituição escolar categoriza e apresenta os saberes sociais por ela definidos e selecionados [...]" (TARDIF, 2014, p. 38).

O último dos saberes relacionados por Tardif (2014) são os experienciais, aqueles saberes que os professores adquirem pela experiência, pelo cotidiano de sua atividade docente. São práticas que vão sendo construídas pela experiência e sendo incorporadas em sua atuação profissional, podendo ser experiências individuais ou do coletivo. Para a compreensão dos saberes plurais de Tardif, da complexidade da docência de Cunha, a pós-graduação stricto sensu em Ensino ou em Educação pode ajudar. E mais especificamente, a pós-graduação em Ensino de Ciências e Matemática, pode contribuir para a formação e desenvolvimento dos profissionais que ensinam Biologia, Química, Física e Matemática.

Para Pimenta e Anastasiou (2014, p. 190) o ensino e a pesquisa são atividades docentes, sobretudo dos professores do ensino superior. Ela argumenta que "como a pesquisa e a produção do conhecimento são objetivos das atividades de pós-graduação, os docentes, quando participam desses programas, sistematizam e desenvolvem habilidades próprias ao método de pesquisa". Ela salienta que é importante o saber ensinar com pesquisa e pesquisar a ação de ensinar. E é na pós-graduação que o professor pode desenvolver habilidades para essas atividades.

Para Cunha (2016, p. 6) várias são as habilidades e capacidades para o exercício da docência, destacamos a relação ensino e pesquisa, 


\begin{abstract}
As habilidades de aliar ensino com pesquisa. Essa condição requer a compreensão da pesquisa como princípio educativo, em que as posturas fundantes das atitudes de inquietação frente ao mundo sejam estimuladas. Envolve competências pedagógicas que privilegiem a dúvida, mais do que as certezas e a capacidade de leitura da realidade associando o conhecimento científico às práticas sociais cotidianas.
\end{abstract}

Ocorre que muitos profissionais chegam às universidades e aos institutos para atuar na educação superior sem experiência docente ou mesmo não tendo sido preparado durante a sua graduação para a atuação em sala de aula. São profissionais de diversas áreas que não cursaram licenciatura e que muitas vezes não conseguem associar nem o ensino e a pesquisa, quanto menos o tripé ensino-pesquisa-extensão. Nesse sentido Hardoim e Mello (2016, p. 105) argumentam que muitos professores são autodidatas e possuem "visões intuitivas de educação". E complementam que esses professores

Sem saber exatamente o que é a docência no ensino superior, sua performance, em
sala de aula e nas demais atividades acadêmicas, inspira-se em modelos de professores
com os quais tiveram contato, os quais admiravam em seu processo de formação e, o
mais temeroso, alguns costumam replicar um ensino baseado em perspectivas
docentes próprias da educação secundarista.

Desse modo, professores que atuam no ensino superior encontram, entre muitos desafios, o desafio de exercer uma profissão para a qual não foi formado, e assim buscam desenvolver-se profissionalmente através de exemplos de experiências vivenciadas anteriormente. Muitos já entram titulados, principalmente nas universidades, e em áreas específicas do conhecimento. Sabem fazer pesquisa naquele campo específico para qual foi formado, no entanto, se deparam com a sala de aula, onde precisam conciliar ensino e pesquisa.

Mas, aqueles professores que chegam às IES ainda sem o título de doutor, possuem a opção de buscar o doutoramento na área de Ensino ou Educação. Nesse sentido, como o estudo de Cunha (2009) citado anteriormente mostrou, existe cada vez mais professores que buscam a qualificação em nível de mestrado ou doutorado em Educação.

\title{
3 Caracterização da Pesquisa
}

A pesquisa teve como objeto a Formação Docente para o Ensino Superior, passando pela pós-graduação, mediante estudo das trajetórias de professores titulados pela REAMEC. Optamos pela metodologia quali-quantitativa por se tratar de um fenômeno que deve ser analisado por diversos ângulos, sendo de grande abrangência e complexidade.

Trata-se de um estudo de caso de abordagem quali-quantitativa, descritivo exploratório. O estudo de caso foi utilizado porque se desejava entender um fenômeno do mundo real e contemporâneo (YIN, 2015). É importante salientar que nos estudos de caso se enfatiza o 
contexto em que ocorrem os fenômenos (GIL, 2009), e que, no caso desse estudo, o contexto se deu na região denominada, por meio de lei, Amazônia Legal.

Sobre a pesquisa quali-quantitativa é notado que,

Ao longo do tempo, a literatura científica vem indicando a importância da utilização das metodologias quali-quantitativas quando existe a necessidade da observação de um fenômeno por diversos ângulos, em função de sua abrangência e complexidade (OLIVEIRA, 2014, p. 9).

A pesquisa possui abrangência, pois os sujeitos foram os vinte e nove doutores titulados pela REAMEC, e apesar de serem egressos de um único programa, eles se encontram em um contexto diverso, de grande dimensão territorial, estão em diferentes estados da região da AL e em diferentes instituições de ensino superior, além de possuírem formações iniciais diferentes. Também é complexo, pois, ao entrevistar pessoas, temos que levar em consideração subjetividades que envolvem os seres humanos.

Para González Rey (2005, p. 5) a pesquisa qualitativa defende um "caráter construtivo interpretativo do conhecimento". Para o autor, a realidade é um sistema complexo e ao nos aproximarmos dessa realidade por meio da nossa pesquisa "formamos um novo campo de realidade em que as práticas são inseparáveis dos aspectos sensíveis dessa realidade”. Para ele, o acesso à realidade é sempre "parcial e limitado a partir de nossas próprias práticas". Temos que compreender a realidade que pesquisamos, mas não somos capazes de nos apropriar da realidade que nos apresenta.

A pesquisa qualitativa será capaz de nos fazer compreender a realidade, o conhecimento, mas não nos apropriar da realidade que está posta. González Rey $(2005$, p. 6) afirma ainda que “o conhecimento é uma construção, uma produção humana, e não algo que está pronto para conhecer uma realidade ordenada de acordo com categorias universais do conhecimento". Assim, utilizamos o termo produção de dados e não coleta de dados para nossa pesquisa.

Em outro texto, González Rey (2011, p. 22) afirma que,

A subjetividade é tão real como qualquer outra forma de existência dos processos e sistemas que aparecem significados no domínio das ciências, como representação da realidade em que vivemos. Porém, desde a perspectiva da produção do saber, a subjetividade representa um sistema gerador que faz parte do ato de saber, o que a diferencia de outros sistemas que não reagem ante a ação metodológica.

Por tanto, ao realizar uma pesquisa com um programa de pós-graduação e entrevistar pessoas, estamos produzindo conhecimento numa situação real, em que os sujeitos reagem diante da nossa prática metodológica durante o estudo.

A Rede havia formado, até dezembro de 2017, setenta e dois doutores, considerando os doutorandos da primeira e da segunda turma. No entanto optamos por selecionar a primeira 
turma, utilizando como critério o tempo decorrido após a defesa e o início da pesquisa, que se deu em 2016, tempo que já é significativo e suficiente para integração dos egressos em programas de pós-graduação e em atividades de pesquisa.

Ao considerarmos neste estudo a questão da subjetividade, apoiamo-nos em Fernando González Rey quando afirma:

\begin{abstract}
O estudo de caso possibilita gerar inteligibilidade sobre a diversidade do singular com base no desenvolvimento de um modelo teórico; neste caso, as configurações subjetivas se tornam, no devir da pesquisa, importante via de explicações e construções abrangentes que geram e permitem novos significados em cada novo caso estudado, garantindo representações cada vez mais complexas e abrangentes sobre o estudado (GONZÁLEZ REY, 2011, p. 21).
\end{abstract}

Temos sujeitos em diferentes contextos regionais e diferentes IES, sendo professores do magistério superior, que trabalham em universidades estaduais, federais e privadas, além de professores da educação básica, técnica e tecnológica, que são os docentes com carreira nos institutos federais, podendo atuar desde o ensino médio integrado à educação profissional até a pós-graduação lato ou stricto sensu.

Os sujeitos foram selecionados após a análise dos resultados da coleta dos dados na plataforma Lattes. Foram entrevistados 11 doutores egressos, de acordo com os seguintes critérios: 1) pelo menos um egresso de cada um dos nove estados que compõem a região; 2) pelo menos 1 dos egressos que migraram da região da Amazônia Legal; 3) egressos que estão atuando em programas de pós-graduação stricto sensu.

Um dos instrumentos de produção de dados utilizado foi o levantamento de informações sócio demográficos, acadêmicos e profissionais; motivações, expectativas e contribuições quanto à escolha e processo de formação; relação da pós-graduação e os impactos no trabalho na universidade/Instituto Federal; pontos positivos, negativos e sugestões de melhoria para o Programa, entre outros. Inserção na Pós-graduação, adesão a grupos de pesquisa e o trabalho em rede.

Para a produção de muitos dos dados referidos no parágrafo anterior, foram utilizadas as plataformas que armazenam informações sobre programas de pós-graduação e grupos de pesquisa, por exemplo, a Plataforma Sucupira, a página do diretório de grupos de pesquisa do CNPq, banco de teses e dissertações da Capes, a Plataforma Lattes e o site do PPGECEM.

Para a produção de dados no Lattes, criamos uma ficha, para que fossem observados os mesmos dados de cada egresso. Os dados produzidos na pesquisa foram: formação inicial, programas de mestrados cursados, instituição de atuação profissional, endereço profissional, data de atualização do currículo (pois pode influenciar no resultado), produção científica 
anterior e posterior a entrada na Rede, participação em projetos e grupos de pesquisa, atuação na formação de professores, orientação e inserção em programas de mestrado, participação em bancas de mestrado e/ou doutorado.

A produção dos dados realizada no Diretório de Grupos de Pesquisas do $\mathrm{CNPq}^{1}$ na plataforma Lattes foi feita por nome do egresso, utilizando-se a opção 'procurar por pesquisador'. Nos casos em que não aparecia resultados de grupos para o egresso, foi tentado buscar ainda com a opção de 'estudante', no entanto, os resultados foram os mesmos. Algumas informações estavam incompletas nos currículos e geravam dúvidas. Quando consideradas relevantes para a pesquisa, entramos em contato com o egresso para eventuais esclarecimentos.

A pesquisa também se caracterizou como descritivo-exploratória, onde um dos instrumentos foi a entrevista. Esta teve por objetivo obter dados pessoais, acadêmicos e profissionais; motivações, expectativas e satisfação quanto à escolha do curso; contribuições para sua trajetória profissional; relação entre formação e trabalho; pontos positivos, negativos e sugestões de melhoria em relação ao PPGECEM/ REAMEC, dentre outros.

As questões foram abertas, visando à garantia da obtenção de material detalhado sobre as percepções dos egressos em relação às questões de investigação. Uma pesquisa descritiva busca conhecer características de determinada população, fenômeno ou estabelecer relações entre variáveis, e a exploratória, segundo Gil (2010), obter maior familiaridade com o problema, aprimorando ideias e/ou descobrindo intuições.

Como afirma Bogdan e Biklen (1994, p. 134), a entrevista "é utilizada para recolher dados descritivos na linguagem do próprio sujeito, permitindo ao investigador desenvolver intuitivamente uma ideia sobre a maneira como os sujeitos interpretam aspectos do mundo".

Para Bardin (2011, p. 93) durante as entrevistas o pesquisador se depara com "uma fala relativamente espontânea, com um discurso falado, que uma pessoa - o entrevistado - orquestra mais ou menos à sua vontade". Para a autora, a subjetividade está muito presente nas falas dos entrevistados, durante seus relatos utilizam-se de seu sistema de pensamento, de sua cognição, seus valores, suas emoções, afetividade, entre outras. Assim, o entrevistado fala a partir de seus referenciais e de suas vivências. Ela ainda cita que "cada pessoa serve-se dos seus próprios meios de expressão para descrever acontecimentos, práticas, crenças, episódios passados, juízos...” (, p. 94)

\footnotetext{
${ }^{1}$ http://lattes.cnpq.br/web/dgp 
A entrevista foi semiestruturada e de forma individual. A estrutura básica da entrevista semiestruturada foi definida previamente, é "[...] um método mais sistemático e ligeiramente pré-planejado que a entrevista não estruturada" (OLSEN, 2015, p. 44).

As entrevistas semiestruturadas são relevantes para se obter dados comparáveis entre os vários sujeitos da pesquisa, no entanto não se tem oportunidade de compreender como os entrevistados estruturariam o tópico pesquisado (BOGDAN e BIKLEN, 1994). A entrevista dá à pesquisa um caráter dialógico entre pesquisador e participante, onde os participantes têm a oportunidade de relatar suas memórias, seus problemas passados e presentes, suas inquietações e suas perspectivas, o texto ganha novos narradores além do pesquisador.

As entrevistas foram agendadas de acordo com a disponibilidade de cada entrevistado, sendo que cinco entrevistas foram presenciais em suas cidades, todos em seus locais de trabalho, e o restante realizadas online. E de acordo com Bogdan e Biklen (1994, p. 48) "os investigadores qualitativos assumem que o comportamento humano é significativamente influenciado pelo contexto em que ocorre, deslocando-se, sempre que possível, ao local de estudo".

Como são longas as distâncias que separam a pesquisadora e os pesquisados, realizamos entrevistas utilizando tecnologias como: chamadas de vídeo pelo aplicativo WhatsApp ou por Skype. Considerando sempre que é importante para uma boa entrevista que o entrevistado se sinta à vontade e possa falar livremente sobre os seus pontos de vista e sua trajetória profissional.

As entrevistas foram gravadas utilizando-se de equipamento específico e transcritas manualmente para que fossem realizadas as análises juntamente com as anotações. De acordo com Yin (2015, p. 114) “o áudio registrado certamente fornece uma interpretação mais precisa de qualquer entrevista do que fazer suas próprias anotações".

Todas as entrevistas foram realizadas por nós, assim mantendo regularidade na forma de condução das mesmas. As transcrições também foram todas realizadas sem auxílio de softwares ou de terceiros. Para o texto final, fizemos a textualização necessária para dar fluidez para o leitor, retirando vícios de linguagem, com o cuidado de não modificar o que cada sujeito disse.

Para as análises dos dados, Bogdan e Biklen (1994, p. 205), escreve que

A análise dos dados é o processo de busca e de organização de transcrições de entrevistas, de notas de campo e de outros materiais que foram sendo acumulados, com o objetivo de aumentar a sua própria compreensão desses mesmos materiais e de lhe permitir apresentar aos outros aquilo que encontrou. 
"As categorias constituem um meio de classificar os dados descritivos que recolheu [...]" (BOGDAN; BIKLEN, 1994, p. 221). Os dados foram categorizados após iniciar a produção, portanto as categorias surgiram durante a produção de dados e no início das análises, não foram definidas previamente.

Os dados quantitativos produzidos para a nossa pesquisa foram analisados pela frequência e porcentagem e os qualitativos, por análise de conteúdo. Para Bardin (2011), a análise de conteúdo, como método, torna-se um conjunto de instrumentos metodológicos de análise das comunicações que utiliza procedimentos sistemáticos e objetivos de descrição do conteúdo das mensagens. A escolha da análise de conteúdo pautou-se no fato de que "a análise de conteúdo oscila entre os dois polos do rigor da objetividade e da fecundidade da subjetividade" (BARDIN, 2011, p.15) e a subjetividade se faz presente na pesquisa que foi realizada, sobretudo nas entrevistas.

A análise de conteúdo é a análise das mensagens, comunicação em que uma das técnicas é a análise categórica temática e seu objetivo "é a manipulação de mensagens (conteúdo e expressão desse conteúdo) para evidenciar os indicadores que permitam inferir sobre uma outra realidade que não a da mensagem" (BARDIN, 2011, p.52).

No caso das análises das entrevistas, Bardin (2011, p.100-106) propõe seis etapas: a) análise temática, em que se divide a entrevista em temas; b) características associadas ao tema central - em que buscamos nas entrevistas encontrar respostas associadas ao tema central da nossa pesquisa; c) análise sequencial, que em cada entrevista foi dividida em sequências em torno dos temas; d) análise das oposições, em que se analisa os discursos opostos de uma mesma entrevista; e) análise da enunciação, que se trata de fazer uma leitura da "maneira de dizer" separada da leitura temática; e f) o esqueleto da entrevista, que é a etapa que simplifica "a complexidade da entrevista por uma estrutura de base, que exprime o esqueleto de um conflito, de uma ambivalência, de um progresso, de uma superação, de uma narração etc.”.

Para organizar a análise de conteúdo, Bardin (2011, p. 125) orienta três etapas: "a préanálise; a exploração do material; e o tratamento dos resultados, a inferência e a interpretação". A primeira etapa, fase de pré-análise, é quando se escolhe o tipo de documento que se vai analisar, que no caso do nosso estudo foram as onze entrevistas com os doutores egressos da REAMEC. Para a referida autora, esta etapa “corresponde a um período de intuições" cujo objetivo é a sistematização de ideias iniciais que vão contribuir com um plano de análise.

A segunda etapa de acordo com Bardin (2011, p. 131), que é a exploração do material, é a fase em que se faz a "codificação, decomposição ou enumeração, em função de regras 
previamente formuladas". A codificação foi a etapa em que escolhemos as unidades em que seriam feitos os recortes do texto. No caso das entrevistas, em vez de numerar os sujeitos, definimos por nomeá-los com nomes de cientistas, para manter o gênero feminino ou masculino.

E a terceira etapa foi a escolha das categorias de análise, para Bardin (2011, p. 148) “classificar elementos em categorias impõe a investigação do que cada um deles tem em comum com outros. O que vai permitir o seu agrupamento é a parte comum existente entre eles”.

Sendo assim, as categorias de análise não foram previamente nomeadas, elas emergiram durante as primeiras análises. Para Bardin (2011, p. 149), a categorização pode ser fornecida antes da análise ou ao final da operação, as categorias podem resultar da "classificação analógica e progressiva dos elementos", ou seja, o "título conceitual de cada categoria só é definido no final da operação". As categorias de análise emergentes foram: trajetória profissional; inserção na pós-graduação; satisfação profissional/pessoal; trabalho em rede; internacionalização; grupos de pesquisa; e identidade docente.

$\mathrm{Na}$ análise de conteúdo, a categorização é um processo estrutural que admite duas etapas. A primeira, chamada de inventário, na qual os elementos são isolados, e a segunda é a classificação na qual os elementos são divididos de forma a organizar as mensagens (BARDIN, 2011).

Na análise dos dados consideramos que "os sentidos subjetivos não aparecem no dizer, mas na organização e nas formas em que as coisas são ditas, na construção mais geral da expressão das pessoas" (GONZÁLEZ REY, 2011, p. 52). Por isso a importância do estudo da subjetividade para compreender os sentidos subjetivos que permeiam os dizeres e respostas dos sujeitos entrevistados.

Nas primeiras análises isolamos os sujeitos e descrevemos a sua trajetória profissional, levando em consideração as categorias que surgiram, e depois, pelas categorias, fizemos a análise em conjunto das respostas dos entrevistados sobre temas que destacamos nas categorias.

Quanto aos dados coletados nos currículos, eles são apresentados somando o conjunto de informações relativos à área de formação inicial e de mestrado, a localização dos sujeitos por unidade federativa antes e depois da titulação, área de atuação e toda a produção bibliográfica antes e depois de 2011. 


\section{Resultados}

Os dados quantitativos, obtidos por meio da coleta de informações nos currículos Lattes dos sujeitos no período de 05 de dezembro de 2016 a 09 de fevereiro de 2017, mostraram evidências de um significativo aumento na produção científica dos doutores egressos. Com a pesquisa foi possível verificar que produziram e publicaram mais quantitativamente, tanto artigos em periódicos quanto livros e capítulos de livros (ALVES; MELLO, 2017).

Além do crescimento na produção bibliográfica sete egressos haviam se credenciado em programas de pós-graduação stricto sensu, o que demonstra que a REAMEC atinge seu objetivo de formar doutores para atuação em mestrados na região da Amazônia Legal. De todos os 72 egressos formados até dezembro de 2017, apenas dois egressos saíram da região amazônica, um para a região sudeste, no estado de Minas Gerais, e outro para o Distrito Federal (ALVES; MELLO, 2017).

Foram realizadas onze entrevistas, sendo sujeitos egressos dos estados brasileiros: Mato Grosso (3); Amazonas (2); Pará (1); Rondônia (1); Tocantins (1); Roraima (1); Amapá (1) e Acre (1). Para proteger a identidade dos sujeitos entrevistados escolhemos nomes de cientistas importantes para representá-los, com a manutenção do gênero. Todas as entrevistas foram gravadas com autorização dos entrevistados e transcrevemos manualmente sem auxílio de softwares. O Quadro 1 apresenta o resumo das análises das entrevistas por categorias.

Quadro 1 - Categorias de análise das entrevistas

\begin{tabular}{|c|c|}
\hline Categorias de análise & Análise das informações \\
\hline Trajetória Profissional & $\begin{array}{l}\text { Dos onze entrevistados, há semelhanças e diferenças nas suas trajetórias. Alguns } \\
\text { conseguiram cursar mestrado e doutorado numa sequência em que não houve muito } \\
\text { tempo de interrupções, mas outros tiveram que esperar um longo tempo, } \\
\text { principalmente para cursar o doutorado. Nem todos queriam ser professores, mas ao } \\
\text { se tornarem professores, foram buscando formas de aprimorar seus conhecimentos, } \\
\text { buscando qualificação profissional nas pós-graduações, e todos atuaram na } \\
\text { educação básica, com exceção de Lise. } \\
\text { Assim como escreve Cunha, } \\
\text { O professor constrói sua performance a partir de } \\
\text { inúmeras referências. Entre elas estão sua história } \\
\text { familiar, sua trajetória escolar e acadêmica, sua } \\
\text { convivência com o ambiente de trabalho, sua inserção } \\
\text { cultural no tempo e no espaço. Provocar que ele } \\
\text { organize narrativas destas referências é fazê-lo viver um } \\
\text { processo profundamente pedagógico, onde sua condição } \\
\text { existencial é o ponto de partida para a construção de seu } \\
\text { desempenho na vida e na profissão (CUNHA, 1997, p. } \\
\text { 189). }\end{array}$ \\
\hline & $\begin{array}{l}\text { Assim, fica evidente que a maioria dos egressos entrevistados não escolheram a } \\
\text { docência como profissão inicialmente, mas foram fatores na vida deles que foram } \\
\text { encaminhando para a profissão. Com o fazer docente foram surgindo as reflexões e } \\
\text { as inquietações que assim os conduziram para a busca por mais conhecimento. Em }\end{array}$ \\
\hline
\end{tabular}




\begin{tabular}{|c|c|}
\hline & $\begin{array}{l}\text { suas falas, mostram as influências das suas trajetórias escolares e acadêmicas, e } \\
\text { mostram como as reflexões sobre sua prática foram importantes no se fazer } \\
\text { professor. }\end{array}$ \\
\hline Grupos de Pesquisa & $\begin{array}{l}\text { Embora a maioria esteja inserida em um ou mais grupos de pesquisa, esses grupos } \\
\text { acontecem dentro de suas IES e com colegas da mesma, ou com os ex-orientadores } \\
\text { da REAMEC. Mesmo compondo, e até mesmo coordenando grupos de pesquisa } \\
\text { com colegas que não cursaram a REAMEC, consideramos importante sua } \\
\text { ocorrência, pois grupos de pesquisa fortalecem a área e ampliam as pesquisas na } \\
\text { região da AL. }\end{array}$ \\
\hline Trabalho em Rede & $\begin{array}{l}\text { Embora alguns egressos tenham participado em bancas de defesa e de qualificação } \\
\text { de mestrado, elas ocorreram mais entre aqueles pertencentes à mesma IES ou que } \\
\text { moram no mesmo Estado. Alegando as longas distâncias e a falta de financiamento, } \\
\text { eles dizem que os contatos são com aqueles colegas que estão mais próximos. } \\
\text { Também não há grupos de pesquisas com outros colegas de diferentes estados. } \\
\text { Entretanto, a egressa Curie diz que, inspirada na compreensão do que é rede, } \\
\text { assumiu uma coordenação de uma rede internacional de pesquisa, além de manter } \\
\text { contato com seu orientador, como acontece com outros egressos, o que já constituiu } \\
\text { uma rede. E percebemos na fala de alguns sujeitos que houve a compreensão de que } \\
\text { a ideia de uma rede é profícua para a pesquisa, sobretudo na região da AL, em que } \\
\text { as distâncias físicas são longas. }\end{array}$ \\
\hline Inserção na Pós-Graduação & $\begin{array}{l}\text { Dos onze entrevistados apenas Rachel e Jane ainda não atuam em programas de } \\
\text { pós-graduação (mestrado). Os outros nove entrevistados atuam, e a maioria estava } \\
\text { com orientações em andamento no período da entrevista em 2017. Essa tríade pós- } \\
\text { graduação/orientação/publicação contribui para o sucesso e consolidação da } \\
\text { REAMEC. }\end{array}$ \\
\hline $\begin{array}{l}\text { Satisfação pessoal e } \\
\text { profissional }\end{array}$ & $\begin{array}{l}\text { Há evidências de satisfação pessoal e profissional, como se estivessem mais } \\
\text { preparados após o doutorado, tanto para as pesquisas como para a atuação docente. } \\
\text { Destacaram as oportunidades que o título de doutor proporcionou para eles, em } \\
\text { estarem participando de pesquisas, poderem conseguir por editais financiamento para } \\
\text { essas pesquisas, convites para bancas de mestrado, convites para palestras, etc. } \\
\text { Muitos relatam a segurança e liberdade na pesquisa que é importante na formação de } \\
\text { um pesquisador, de um doutor. }\end{array}$ \\
\hline Identidade Docente & $\begin{array}{l}\text { Com exceção de uma egressa, os demais não queriam ser professores, tanto que não } \\
\text { escolheram como profissão. A docência foi acontecendo durante a trajetória pessoal } \\
\text { e fatores como oportunidades de trabalho foram os conduzindo por essa carreira, } \\
\text { fazendo com que hoje se reconheçam como docentes e afirmem gostar do que } \\
\text { fazem, e hoje já não se veem exercendo outra profissão. É perceptível nas falas dos } \\
\text { egressos como o doutorado oportunizou a eles uma identidade docente, pois } \\
\text { afirmam ter melhorado a atuação, sendo que todos os onze atuam em cursos de } \\
\text { licenciatura. Como dito por Lasky (2005) a identidade do docente tem relação com } \\
\text { a construção do ser profissional que pode ser influenciado por suas vivencias, pelos } \\
\text { contextos durante toda a sua carreira. As experiências vivenciadas na REAMEC, os } \\
\text { saberes construídos nas disciplinas e durante as pesquisas tem influência na } \\
\text { formação do ser professor, e nas falas dos egressos, o doutorado os fortaleceram } \\
\text { como docentes, dando mais segurança para a atuação docente e para a pesquisa. } \\
\text { Cunha (2009, p. 83) diz que "a docência é uma atividade complexa, que exige tanto } \\
\text { uma preparação cuidadosa, como singulares condições de exercício, o que pode } \\
\text { distingui-la de algumas outras profissões". Eles se dizem mais seguros no exercício } \\
\text { complexo da profissão docente, e atingiram um nível de compreensão maior da } \\
\text { atividade que exerce. }\end{array}$ \\
\hline Internacionalização & $\begin{array}{l}\text { Apenas um egresso entrevistado conseguiu fazer intercâmbio em outro país, no } \\
\text { entanto, alguns conseguiram participar de eventos internacionais. Descartes que foi } \\
\text { o único egresso que fez intercâmbio, ainda permanece no grupo de pesquisa da } \\
\text { Espanha, país onde realizou parte de seus estudos, e mantém contato, importante } \\
\text { trabalho em rede, indo novamente em encontros para estudos, além de conseguir } \\
\text { trazer pesquisadores de lá para palestrar em sua IES. }\end{array}$ \\
\hline
\end{tabular}

Fonte: Dados da Pesquisa - Elaboração das autoras. 
O fato de não terem a profissão docente como escolha é mais comum do que se imagina. Dados do Exame Nacional de Desempenho de Estudantes (ENADE) de 2005 mostraram que menos de $50 \%$ dos licenciandos respondem estar no curso por querer ser professor. Para Gatti (2010, p. 1361)

\footnotetext{
A escolha da docência como uma espécie de "seguro desemprego", ou seja, como uma alternativa no caso de não haver possibilidade de exercício de outra atividade, é relativamente alta $(21 \%)$, sobretudo entre os licenciandos de outras áreas que não a Pedagogia.
}

A profissão docente é, para a maioria, uma opção caso não consiga fazer algo que considerem mais rentável. Muitos julgam a profissão como sendo difícil e pouco reconhecida. No mesmo estudo de Gatti (2010), ela mostra que os estudantes dos cursos de licenciatura são maioria de escolas públicas, filhos de pais com baixa escolaridade. São geralmente estudantes que precisam trabalhar, por isso optam por cursos de licenciatura no período noturno.

Destacamos também algumas subcategorias, apontamentos identificados nas falas de vários sujeitos, tais como: financiamento para participar do curso, publicações pósdoutoramento, entendimento da região da AL, cursar doutorado sem precisar sair da AL.

Acerca do financiamento para participação das várias etapas do curso, vários sujeitos apontaram a dificuldade em obter recursos para participar das disciplinas obrigatórias e optativas, dos Seminários de Pesquisa I e II, que ocorrem em Belém e Manaus, respectivamente, e de eventos nacionais e internacionais. Sujeitos como Rachel, Descartes, Curie, Lise, Jane, Marx e Euclides relataram durante as entrevistas que muitos colegas não conseguiram receber diárias, passagens ou qualquer apoio de suas instituições. Mesmo entre os sujeitos que receberam, eles destacaram que viram os colegas passarem dificuldades, interromper disciplina por falta de recursos financeiros para se manterem durante o período das disciplinas.

Alguns apontaram ainda como não ter conseguido participar de eventos influenciou na formação, uma vez que participar dos eventos acarreta mais conhecimento acadêmico e cultural. E com os apontamentos dos sujeitos, verificamos que cada IES credenciada trata de forma diferente os doutorandos, tanto em relação a ajuda de custo para as viagens e participação nas disciplinas e eventos, quanto em relação ao afastamento das atividades nas IES. Há IES que liberam afastamentos de 1 ano, de 2 anos, as que apenas dão afastamento parcial e as que não possibilitam qualquer tipo de afastamento durante a escrita da tese.

A diferenciação no tratamento dos doutorandos por parte de cada IES é um fator que precisa ser considerado no credenciamento na Rede, faz-se necessário propor melhorias no sentido de que todos os doutorandos possam participar plenamente das atividades curriculares 
do PPGECEM, além de poderem participar de eventos científicos que ampliem a sua formação. O financiamento é necessário para facilitar a mobilidade dos doutorandos e a manutenção da rede entre os pesquisadores egressos da REAMEC.

Como observamos no levantamento das publicações feitas pelos currículos Lattes dos egressos, houve crescimento na produção de artigos, livros e trabalhos em eventos. Na fala dos entrevistados, eles destacam que a produção científica deles mudou, mas argumentam que a principal mudança foi em relação a qualidade dos textos produzidos, a segurança na escrita que foi proporcionada pelo curso de doutorado e pela titulação recebida. Há aqueles que salientam que o fato de orientar em programas de pós-graduação diminui a escrita individual, mas publicam muito com seus orientandos.

Nas entrevistas, eles destacam que melhoraram suas publicações não só em número, mas que são trabalhos que têm sido mais criteriosamente elaborados e que os egressos ganharam mais confiança para escrever após o doutorado. E esse aumento quantitativo deve-se a possibilidade de orientar trabalhos que estão sendo publicados, chegando a dizer que poucos estão escrevendo isolados, que as produções são mais com os seus orientandos do que individuais.

As publicações em parcerias com seus orientandos e com seus ex-orientadores beneficia a Rede na avaliação realizada pela Capes. Na última avaliação do quadriênio, ficou evidente que a REAMEC é o programa que mais produziu em relação aos programas acadêmicos brasileiros, como está ilustrado na Figura 4 que é um recorte do Relatório da Capes sobre os indicadores de produção científica.

Figura 4 - Pontos por estrato e tipo de produção

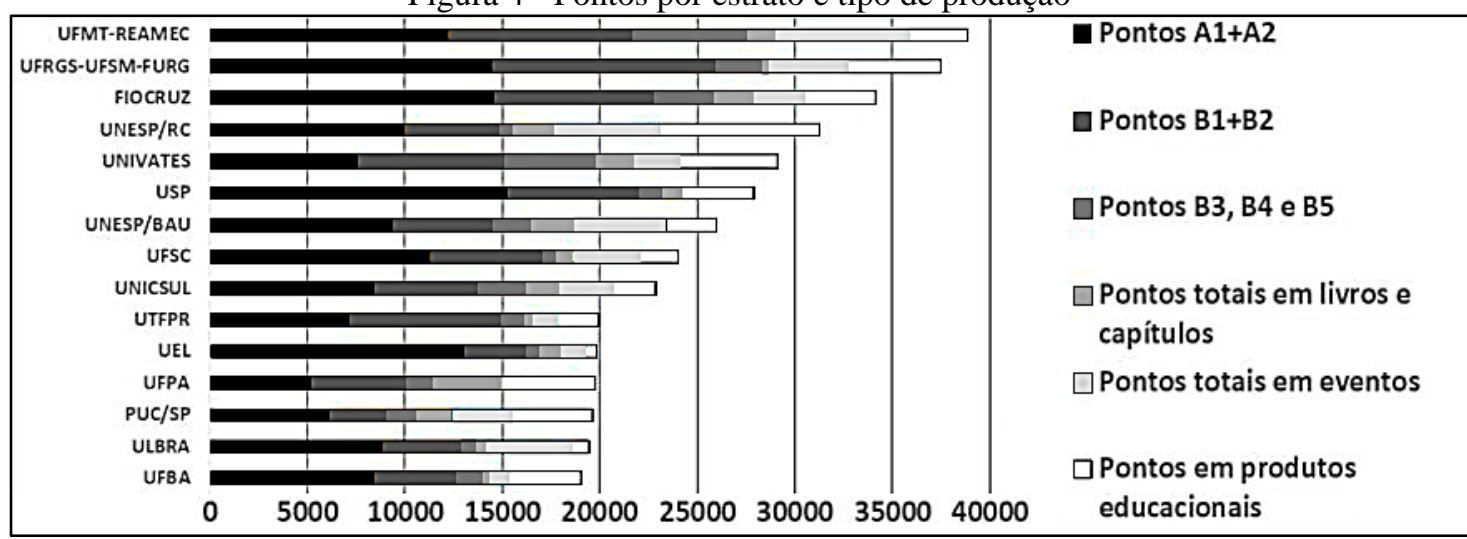

Fonte: Brasil (2017a, p. 54).

Como vemos na Figura 4, a REAMEC obteve mais de 35 mil pontos somando todos os tipos de produção com destaque para os estratos A1 + A2 e B1 + B2. Mesmo com a falta de 
recursos apontada pelos egressos, todavia, o programa é o que mais pontuou em publicação em eventos, além de atingir aproximadamente 2,5 mil pontos em produtos educacionais.

Outra subcategoria, o entendimento da região da AL, mostrada nas falas de egressos como Curie, Marx, Descartes, Darwin e Euclides, que destacam vantagens em se fazer um doutorado com docentes doutores credenciados na REAMEC, que atuam na região amazônica e, por isso, compreendem as dificuldades em se fazer pesquisa e atuar nessa região. Para os egressos, foi enriquecedor poder cursar o doutorado na região onde atuam, pois discutiam seus desafios de trabalhar e pesquisar na região com doutores experientes e conhecedores dos mesmos desafios.

Pelas distâncias entre os polos e IES da região da AL, é importante que o trabalho em rede seja efetivado, pois ampliará o número de colaborações de pesquisa, ampliando a produção de conhecimento na área de Ensino de Ciências e Matemática. E cabe ressaltar que, antes da REAMEC, muitos doutores e doutorandos não realizavam pesquisas com olhar voltado para a AL, não buscavam a compreensão da região e das pesquisas para a região.

A subcategoria cursar doutorado sem precisar sair da AL foi apontada também por vários sujeitos entrevistados: Rachel, Descartes, Lise, Euclides e Jane, o que demonstra que o quanto a REAMEC tem um papel essencial para essa região, pois não havia possibilidades em se tornar doutor/doutora em Educação em Ciências e Matemática sem sair da região Amazônica. Retomando a fala de Rachel (2017) “se eu tivesse feito um doutorado em educação na época, teria que ter saído para fazer um doutorado fora do contexto Amazônia, e teria que estudar com pessoas que não entendiam a nossa realidade da Amazônia”.

Assim, os egressos reforçam que, sem a REAMEC, teriam que ter ido fazer doutorado nas regiões sul ou sudeste, o que para muitos não era possível por diversos motivos, em programas de outras regiões não realizariam o exercício de olhar para a região e entender as pesquisas que são realizadas na AL. Sair da sua região para estudar fora é ter que mudar seus hábitos, levar a família ou se afastar desta, conhecer outras realidades. Mas, ao voltar para sua região, provavelmente sentiria a necessidade de compreender o seu contexto, sua realidade, que é diferente de onde teria estudado.

A “evasão insignificante” (BRASIL, 2017, p.2) apontada no relatório de avaliação da REAMEC pode estar relacionada com o fato do doutorando não precisar mudar seu domicílio, assim conseguem conciliar trabalho e os estudos na pós-graduação, em especial pela modalidade de disciplinas condensadas em períodos de férias docentes. 
Além das categorias e subcategorias já discutidas, um ponto relevante e destacado por alguns sujeitos, como Darwin e Euclides, é o acolhimento e o tratamento dos docentes da Rede, que sempre tratam os doutorandos como colegas de profissão, de forma cordial e respeitosa, uma vez que todos já eram docentes do ensino superior.

Retomando a questão da não efetividade do trabalho em rede, entendida por muitos, sobretudo apontando como principal fator o financiamento, recorremos ao projeto do curso, analisando quais ações poderiam ser realizadas para a concretização da rede. Identificamos em algumas falas da turma estudada que houve referência a disciplinas não ministradas por professores de outros polos, orientação fora do sistema em rede, como é o caso de Maria que foi orientado por doutor de sua própria IES de trabalho. Em sua fala, e na de Galileu, comentam que morar na mesma cidade do orientador facilitam os encontros presenciais, o que não ocorre com a maioria dos doutorandos, que geralmente têm seus orientadores em IES ou polos diferentes.

No projeto não prevê e também não há proibição quanto a orientadores e orientandos serem do mesmo polo, o que acontece, mas é importante o relacionamento da rede, com as orientações funcionando de forma que todos os polos e IES interajam para a formação dos doutores, o que poderá facilitar a manutenção da rede posterior a esta formação.

\section{CONSIDERAÇÕES FINAIS}

O estudo buscou responder como o programa de Pós-Graduação em Educação em Ciências e Matemática da REAMEC promoveu mudanças na trajetória profissional na docência universitária do doutor egresso e colabora para que o egresso permaneça trabalhando em rede e mantendo grupos de pesquisa interinstitucionais para a região da Amazônia Legal.

As principais mudanças que foram apontadas pelos entrevistados foram a segurança durante a atuação profissional e as oportunidades que foram surgindo após a titulação de doutor. Muitos ingressaram em programas de pós-graduação, estão em grupos de pesquisas, recebem convites para palestras e participação de eventos, de bancas de qualificação e de defesa de mestrados e doutorados, além da melhora da condição financeira.

Assim, o programa em rede, PPGECEM/REAMEC, contribuiu para a inserção de doutores em programas de mestrado como docentes e orientadores, contribuindo para o aumento da produção científica dos mesmos, sobretudo na região amazônica, e que novos mestrados foram constituídos com a formação dos doutores da primeira turma. E, apesar da formação em rede, em sua maioria, os egressos continuam isolados e não mantém os trabalhos 
e pesquisas em rede, demonstrando que a formação por si só não é fator determinante para tal configuração. De modos que, entender os fatores que influenciam e propiciam a formação de redes na área em tela, constitui-se elemento importante para uma avaliação do PPGECEM/REAMEC.

Os dados produzidos com a pesquisa realizada nos currículos Lattes dos egressos mostrou que houve crescimento de produção tanto de artigos em periódicos com Qualis, quanto em livros, capítulos de livros e outras produções, além dos relatos durante as entrevistas que eles apontam que, além do número de publicações, elas melhoraram em termos qualitativos. Nos resultados verificamos que nove dos egressos entrevistados estão atuando em programas de pós-graduação stricto sensu como docentes e ou orientadores.

Pelos relatos obtidos por meio das entrevistas, a Rede não se concretiza em uma plenitude, pois não são desenvolvidos trabalhos e produções em parcerias, os poucos contatos que se tem não são no sentido profissional, e sim pessoal. Muitos reforçam a questão do financiamento que não há por parte das IES de origem dos doutorandos. O que tem ocorrido, com pouca frequência, é a participação de egressos em bancas de qualificação e defesa de dissertações de orientandos daqueles que conseguiram se inserir em programas de pósgraduação.

Apesar de continuarem publicando, produzindo, inseridos em grupos de pesquisa, esses egressos o têm feito de forma isolada ou com colegas de instituição. Não conseguiram após a conclusão do curso de doutorado manter os contatos, a ponto de produzirem em conjunto e manter uma integração em rede. Todos afirmam a importância da Rede na região, que gostariam de fazer mais contatos, no entanto as distâncias e a falta de recursos financeiros muitas vezes impedem que o funcionamento em rede se estabeleça.

A necessidade da Rede em formar doutores da Amazônia para atuação na região vem se mostrando eficiente, uma vez que apenas dois doutores egressos saíram da região. Foram 72 doutores formados até dezembro de 2017, os 70 doutores que continuam na região estão distribuídos entre os estados: o Pará e o Amazonas já receberam 17 e 16 doutores, respectivamente; no Mato Grosso foram 13; Rondônia e Maranhão, 7 cada um; Roraima 4; Amapá, Acre e Tocantins, 2 cada um deles.

O número de doutores formados até 2017 mostra que a REAMEC conseguirá atingir sua meta inicial de formar 150 doutores para a região, uma vez que a terceira e quarta turma juntas somam 90 doutorandos. Observando que a terceira turma, com 58 doutorandos (houve 
dois desistentes), tem previsão para defesas no decorrer do ano de 2018 e o edital aberto em 2018 oportuniza mais 60 novas vagas para início em 2019.

A avaliação da Comissão da Área de Ensino da Capes para o Quadriênio 2013-2016 mostrou que o PPGECEM/REAMEC se consolidou na formação de doutores para a região. O programa foi avaliado com 'Muito Bom' em todos os quesitos que foram avaliados, portanto, recebeu nota 5 , e foi ressaltado pela comissão que tem todos os índices para receber nota 6 , que só não ocorreu por decisão interna da comissão de avaliação da área de Ensino. Ademais o programa foi apontado, pela comissão de avaliação da Capes, como exemplo positivo para formar doutores e que pode servir de modelo para outras áreas do conhecimento.

O estudo mostrou o impacto da Rede para a região da Amazônia Legal, formando doutores da região para transformar o ensino, pesquisa e extensão na área de Ensino de Ciências e Matemática, além de atuarem diretamente com a formação de professores para a Educação Básica. Evidencia também que, pelas limitações que a grande extensão territorial impõe aos doutores e doutorandos, é preciso o investimento por parte das IES e da Capes para a continuidade de um trabalho reconhecido como de muita importância.

Finalizamos nossas considerações com uma proposta para que a REAMEC organize um evento periódico para os egressos, com a finalidade de criar e fortalecer redes de pesquisa entre os doutores egressos, dar visibilidade as produções dos mesmos, podendo até fazer edições especiais da revista editada pela REAMEC, compor a comissão científica do evento com os doutores docentes e doutores egressos formados pela Rede, além de propor diálogos para que as IES cheguem a um consenso para que os doutorandos tenham o mesmo tratamento durante o doutorado, independente da IES.

\section{REFERÊNCIAS}

ALVES, Ana Claudia Tasinaffo; MELLO, Irene Cristina de. Amazonian Education Network in Sciences and Mathematics: Impacts in PhD formation for networking. Revista Prática Docente, v. 2, n. 2, p. 219-235, 2017. Disponível em: http://periodicos.cfs.ifmt.edu.br/periodicos/index.php/rpd/article/view/107. Acesso em: 30 jan. 2018.

BARDIN, Laurence. Análise de Conteúdo. São Paulo: Edições 70, 2011.

BOGDAN, Robert, BIKLEN, Sari. Investigação Qualitativa em Educação: Uma Introdução à Teoria e aos Métodos. Porto, Portugal: Porto Editora, 1994.

BRASIL. Ficha de Avaliação da REAMEC. Área de Ensino. Avaliação Quadrienal. CAPES, Brasília, DF, 2017. 
BRASIL. Relatório de Avaliação: ENSINO. Avaliação Quadrienal. CAPES, Brasília, DF, 2017a. Disponível em: https://capes.gov.br/images/stories/download/avaliacao/relatoriosfinais-quadrienal-2017/20122017-ENSINO-quadrienal.pdf. Acesso em: 24 mai. 2018.

BRASIL. Censo da Educação Superior 2017: divulgação dos principais resultados.

MEC/INEP, Brasília, 2018. Disponível em: http://portal.mec.gov.br/docman/setembro-2018pdf/97041-apresentac-a-o-censo-superior-u-ltimo/file. Acesso em: 30 mai. 2019.

CUNHA, Maria Isabel da. Conta-me agora! As narrativas como alternativas pedagógicas na pesquisa e no ensino. Revista da Faculdade de Educação, São Paulo, n. 1/2, 1997.

Disponível em: http://www.scielo.br/scielo.php?pid=S0102-

25551997000100010\&script=sci_arttext. Acesso em: 27 jun. 2018.

CUNHA, Maria Isabel da. Docência na universidade, cultura e avaliação Docência na universidade, cultura e avaliação institucional: saberes silenciados em questão. Revista Brasileira de Educação, v. 11, n. 32, maio-ago. 2006. Disponível em: http://www.scielo.br/pdf/\%0D/rbedu/v11n32/a05v11n32.pdf. Acesso em: 21 jun. 2018.

CUNHA, Maria Isabel da. O lugar da formação do professor universitário: o espaço da pósgraduação em educação em questão. Revista Diálogo Educacional, Curitiba, v. 9, n. 26, p. 81-90, jan-abr, 2009. Disponível em:

http://www2.pucpr.br/reol/pb/index.php/dialogo?dd1=2585\&dd99=view\&dd98=pb. Acesso em: 21 jun. 2018.

CUNHA, Maria Isabel da. Prefácio. In: MELLO, I. C. (org.) A Formação Docente para o Ensino Superior. Cuiabá, EdUFMT/Editora Sustentável, 2016. Série de e-books COGRAD/ANDIFES, vol. 1. Disponível em:

http://editorasustentavel.com.br/aformacaodocenteparaoensinosuperior/. Acesso em 21 jun. 2018.

GATTI, Bernadete. Formação de Professores no Brasil: características e problemas.

Educação e Sociedade, Campinas, v. 31, n. 113, p. 1355-1379, out-dez, 2010. Disponível em: http://www.cedes.unicamp.br. Acesso em: 17 mai. 2017.

GIL, Antônio Carlos. Estudo de Caso. São Paulo: Atlas S.A., 2009.

GIL, Antônio Carlos. Como elaborar Projetos de Pesquisa. 5. ed. São Paulo: Atlas S.A., 2010

GONZÁLEZ REY, Fernando. Pesquisa Qualitativa e Subjetividade: Os processos de construção da informação. São Paulo: Pioneira Thomson Learning, 2005.

GONZÁLEZ REY, Fernando. Subjetividade e Saúde: superando a clínica da patologia. São Paulo: Cortez, 2011.

HARDOIM, Edna Lopes; MELLO, Irene Cristina de. Curso de Docência no Ensino Superior: a experiência da UFMT na formação continuada de seus professores. In: MELLO, Irene Cristina (org.) A Formação Docente para o Ensino Superior. Cuiabá, EdUFMT/Editora Sustentável, 2016. Série de e-books COGRAD/ANDIFES, vol. 1. Disponível em: 
http://editorasustentavel.com.br/aformacaodocenteparaoensinosuperior. Acesso em: 21 jun. 2018.

LASKY, Sue. A sociocultural approach to understanding teacher identity, agency and professional vulnerability in a context of secondary school reform. Teaching and Teacher Education, v. 21, p. 899-916, 2005. Disponível em:

https://www.sciencedirect.com/science/article/pii/S0742051X0500079X. Acesso em: 02 abr. 2017.

OLIVEIRA, Luciana Rodrigues. Contribuições do programa de pós-graduação em educação da UNICAMP para a trajetória profissional de mestres e doutores: percepções de egressos titulados. Tese (Doutorado em Educação), Universidade Estadual de Campinas, Campinas, 2014. Disponível em:

http://repositorio.unicamp.br/jspui/handle/REPOSIP/254112. Acesso em: 31 mar. 2016.

OLSEN, Wendy. Coleta de dados: Debates e métodos fundamentais em pesquisa social. Porto Alegre: Penso, 2015.

PIMENTA, Selma Garrido; ANASTASIOU, Léa da Graças Camargos. Docência no Ensino Superior. São Paulo: Cortez, 2014.

SILVA JUNIOR, João Dos Reis; FERREIRA, Luciana Rodrigues; KATO, Fabíola Bouth Grello. Trabalho do professor pesquisador diante da expansão da pós-graduação no Brasil pós-LDB. Revista Brasileira de Educação, Rio de Janeiro, v. 18, n. 53, p. 435-456, jun. 2013. Disponível em http://www.scielo.br/scielo.php?script=sci_arttext\&pid=S1413$24782013000200011 \& \operatorname{lng}=$ pt\&nrm=iso. Acesso em 08 jan. 2018.

TARDIF, Maurice. Saberes Docentes e Formação Profissional. 17. ed. Petrópolis, RJ: Vozes, 2014.

VELLOSO, Jacques. Mestres e Doutores no país: destinos profissionais e políticas de pósgraduação. Cadernos de Pesquisa, v. 34, n. 123, p. 583-611, set-dez 2004. Disponível em: http://www.scielo.br/pdf/\%0D/cp/v34n123/a05v34123.pdf. Acesso em: 24 jun. 2018.

VIOTTI, Eduardo Baumgratz; et al. Titulados. In: BRASIL, Mestres e Doutores 2015.

Estudos da demografia da base técnico científica brasileira. - Brasília, DF: Centro de Gestão e Estudos Estratégicos, 2016. Disponível em:

https://www.cgee.org.br/documents/10182/734063/Mestres_Doutores_2015_Vs3.pdf. Acesso em: 25 jun. 2018.

YIN, Robert K. Estudo de Caso: Planejamento e Métodos. 5. ed. Porto Alegre: Bookman, 2015.

Recebido em: 8 de agosto de 2020.

Aprovado em: 14 de dezembro de 2020. 